\title{
VISUALIZATION OF SYNTHETIC JETS AT HIGHER STOKES NUMBERS
}

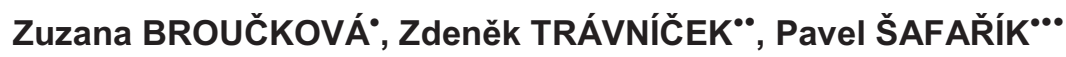

\begin{abstract}
Visualization of synthetic jets at higher Stokes numbers ( $S=90$ and 127) by the phase-locked smoke-wire technique is presented and discussed. The working fluid is air. The Reynolds numbers are quantified using hot-wire anemometry. Although our method of visualization essentially provides only qualitative results, the present study also demonstrates some quantitative results, namely the behavior of the zero-net-mass-flux jet near its critical stage. Visualization of the sub-critical stage is also shown.
\end{abstract}

\section{INTRODUCTION}

Flow visualization is a typical initial step of many studies in experimental fluid mechanics. The reason consists in the fact that it can significantly elucidate mechanisms involved in flow fields [1-3]. Because it gives a general view of the flow field, it can be helpful in the choice of flow parameters and regions of interest for subsequent local point measurements. Moreover, the visualization can be very beneficial for a precise adjustment of a chosen flow field situation in the test section. For visualization in air, the smoke-wire technique is very useful and versatile method of experimentalists [4-6].

A synthetic jet (SJ) is a fluid flow generated from oscillating fluid. The time-mean mass flux of the oscillatory flow in the orifice is zero, hence the other common expression is the zero-net-mass-flux jet. The first SJ actuator (in today's terminology) was most likely a laboratory air-jet generator designed and used by Dauphinee [7]. Since the end of the last century, the topic has been the subject of intensive investigations [8-14]. Recently, $\mathrm{S} J$ has become a popular research topic because of its promising advantages for various applications of heat transfer [15-25], active flow control (jet vectoring and active flow control in external and internal aerodynamics), and mixing. Note that another variant of

\footnotetext{
- Zuzana Broučková, Institute of Thermomechanics AS CR, Dolejškova 5, 18200 Prague 8, CTU Faculty of Mechanical Engineering, Technická 4, 16607 Prague 6, zuzana.brouckova@tiscali.cz

•-Zdeněk Trávníček, Institute of Thermomechanics AS CR, Dolejškova 5, 18200 Prague 8, tr@it.cas.cz

..P Pavel Šafařík, Institute of Thermomechanics AS CR, Dolejškova 5, 18200 Prague 8, CTU Faculty of Mechanical Engineering, Technická 4, 16607 Prague 6, pavel.safarik@fs.cvut.cz
}

This is an Open Access article distributed under the terms of the Creative Commons Attribution License 2.0, which permits unrestricted use, distribution, and reproduction in any medium, provided the original work is properly cited. 
the SJ actuator, which generates a non-zero-net-mass-flux jet (called the hybrid SJ), was recently designed and investigated [26-30].

The SJs are usually considered a promising tool for applications under very small scales, e.g. microchannels of microelectromechanical systems, MEMS, [24, 25]. This implies low Reynolds and Stokes numbers ( $R e$ and $S$, defined in paragraph 3.1 below). On the other hand, large-scale applications with high Reynolds and Stokes numbers could be beneficial. For example, an implementing of active flow control systems, including SJs, on civil transport aircrafts is discusses by Jabbal et al. [31], and they considered incredibly large scales: Airbus A320 with the wing span of $34 \mathrm{~m}$, and the maximum takeoff mass of $77100 \mathrm{~kg}$.

The motivation of the present study is an evident lack of experimental data for SJs at higher Stokes numbers $(S>100)$ in the available literature.

\section{EXPERIMENTAL SETUP AND METHODS}

Recently, the model shown in Fig. 1 was developed for a systematic investigation of a formation criterion of SJs, which quantifies a necessary condition for the existence of the time-mean jet flow by means of the "jet synthesis process" (Holman et al. [32]). The results of the recent study is described somewhere else [33].

Figure 1 shows the geometry of the present SJ actuator, including the coordinate system $x, r$. The cavity is made of a Perspex tube with a 5 -mm-thick wall, an inner diameter of $60 \mathrm{~mm}$, and a length of $410 \mathrm{~mm}$. The sharp-edged orifice has a diameter of $D=$ $20.2 \mathrm{~mm}$, is made of a $4.75-\mathrm{mm}$-thick Perspex plate, and is oriented vertically upward. The electrodynamically driven diaphragm with a diameter of $D_{\mathrm{D}}=63 \mathrm{~mm}$ originates from the loudspeaker (MONACOR SP-45/4, electrical power rating 20W). The working fluid is air at barometric pressure and room temperature $(20 \div 23)^{\circ} \mathrm{C}$. To assure the constant operating temperature of the loudspeaker coil, its back side is cooled by an active heat sink (see [33] for more details).

The smoke-wire technique is used for flow visualization. The smoke-wire (SW) is uniformly twisted from three resistance wires with $0.1 \mathrm{~mm}$ in diameter, located across the investigated SJ, coated with liquid (Fog Fluid, DANTEC) before each test, and heated by the Joule effect of the direct electric current - $[5,6]$. The liquid is evaporated from the SW, and condensed by air stream speedily. White filaments, which trace the airflow, are traditionally called a "smoke". In fact, filaments consist of tiny droplets of aerosol with a typical diameter $1 \mu \mathrm{m},[3,5]$. The test section is illuminated either by the (A) phase-locked stroboscope light or by the (B) single shot of the flashlight:

(A) Phase-locked stroboscope light (Cole Parmer 87002) shows phase-locked streaklines. The flowfield patterns are observed and photographed by a digital camera (Canon PowerShot G7) under a $(0.25 \div 1.0) \mathrm{s}$ exposition. The resulting photo is a multi-exposition of many frames (typically from 25 to 100 frames), which shows the phase-locked feature of the flow field while smoothing out the fluctuation deviations of the individual cycles.

(B) The single shot of the flashlight gives an instantaneous pattern of flow field in form of streaklines. 


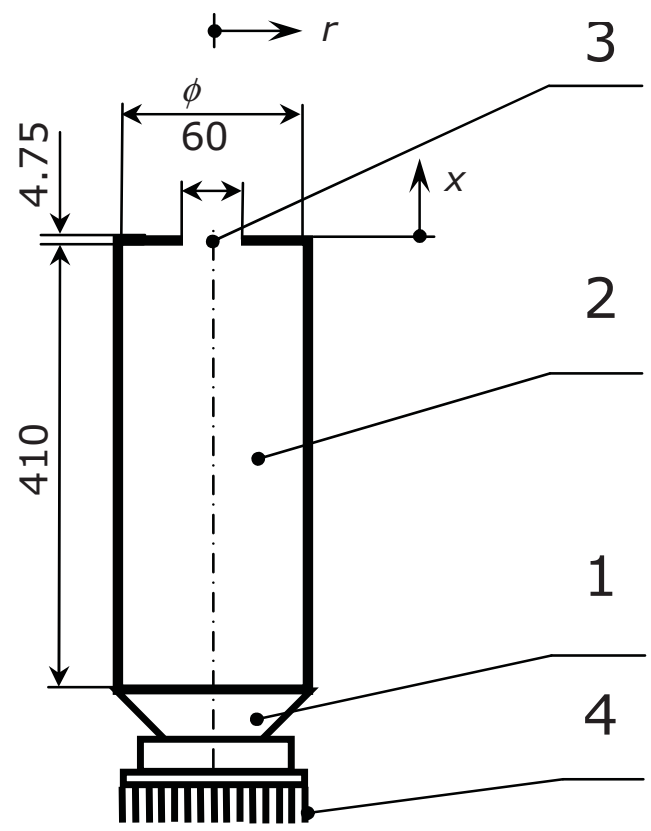

Figure 1: Schematic of the synthetic jet actuator [5]: 1- loudspeaker, 2- cavity, 3- orifice, 4- active heat sink.

Hot-wire anemometry is used to measure the velocity Anemometer DANTEC MiniCTA $55 T 30$ in constant temperature anemometry (CTA) mode with a single-sensor wire probe (55P16). The sampling frequency and the number of samples are $(3 \div 30) \mathrm{kHz}$ and 8192 , respectively. The calibration range is $(0.6 \div 20) \mathrm{m} / \mathrm{s}$, and the linearization error of the calibration (using a four-degree polynomial) is within $6.7 \%$. The phase averaging of the velocity during one cycle was performed using the velocity decomposition $u=U+U_{\mathrm{f}}+u^{\prime}$, where $U$ is the time-mean velocity, $U_{\mathrm{f}}$ is the periodic phase-locked component, and $U^{\prime}$ is the fluctuation component. Considering the reciprocating velocity character at the actuator orifice, the positive (extrusion) and the negative (suction) flow orientations were assumed, and the velocities during the suction stroke were inverted to reflect the flow direction. Data processing is performed in MATLAB.

An auxiliary experiment is made using the Pitot tube (diameter of $2 \mathrm{~mm}$ ) and an electronic manometer (Greisinger GMH 3156).

\section{ResUltS AND DISCUSSION}

\subsection{Parameters}

Assuming the slug flow model [32], two characteristic length scales of the axisymmetric SJ are the output orifice diameter $D$ and the "stroke length" $L_{0}=U_{0} T$, where $T$ is the time period ( $T=1 / f$, where $f$ is frequency), and $U_{0}$ is the time-mean orifice velocity defined from the orifice centerline velocity at the axis $(r=0)$, see e.g. Smith and Glezer [9], Trávníček et al. [26]: $U_{0}=\frac{1}{T} \int_{0}^{T_{E}} u_{0}(r=0, t) d t$, where $T_{\mathrm{E}}$ is the extrusion time (e.g., $T_{\mathrm{E}}=T / 2$ at a common sinusoidal waveform of $\left.u_{0}(t)\right)$ and $u_{0}$ is the velocity at the orifice exit.

The Reynolds number are defined as $\operatorname{Re}_{U 0}=U_{0} D / v, R e=U D / v$, where $U$ is the time- and spatial-averaged orifice velocity during the discharge stroke - Holman et al. [32]. 
Considering the slug flow model and the sinusoidal waveform of the velocity cycle in the orifice, the following relations can be derived: $\bar{U}=2 U_{0}, R e=2 R e_{U_{0}}$, and $S t=\pi D / L_{0}$. The Stokes number is defined as $S=\sqrt{\operatorname{ReSt}}=D \sqrt{2 \pi f / v}$.

\subsection{Frequency characteristics of the actuator}

This auxiliary experiment is made using the Pitot tube. CTA is also used for comparison purposes (CTA probe was located at the same position as the Pitot tube). The time-mean velocity is measured on the axis, downstream from the actuator orifice, at a moderate distance from the exit $x=6.7 D$, where the periodic velocity component is not dominant $[9,26]$.

Figure 2 shows the time-mean velocity, which is measured in the range of the actuating frequency $10 \mathrm{~Hz}-930 \mathrm{~Hz}$ at the constant electrical power of $20 \mathrm{~W}$. Two significant maxima of the velocity are approximately $13 \mathrm{~m} / \mathrm{s}$ and $6 \mathrm{~m} / \mathrm{s}$. They show the resonances at $(125 \div 175) \mathrm{Hz}$ and $510 \mathrm{~Hz}$. Note that the theoretical first and second natural frequencies were evaluated $f_{1}=172 \mathrm{~Hz}$ and $f_{2}=192 \mathrm{~Hz}$ (see Kordík et al. [34] for more details), which are reasonably close to the first experimental maximum - as is depict in Fig. 2. The values measured by the Pitot tube agree well with the CTA results. Bigger differences can be only found in the area of the first maximum.

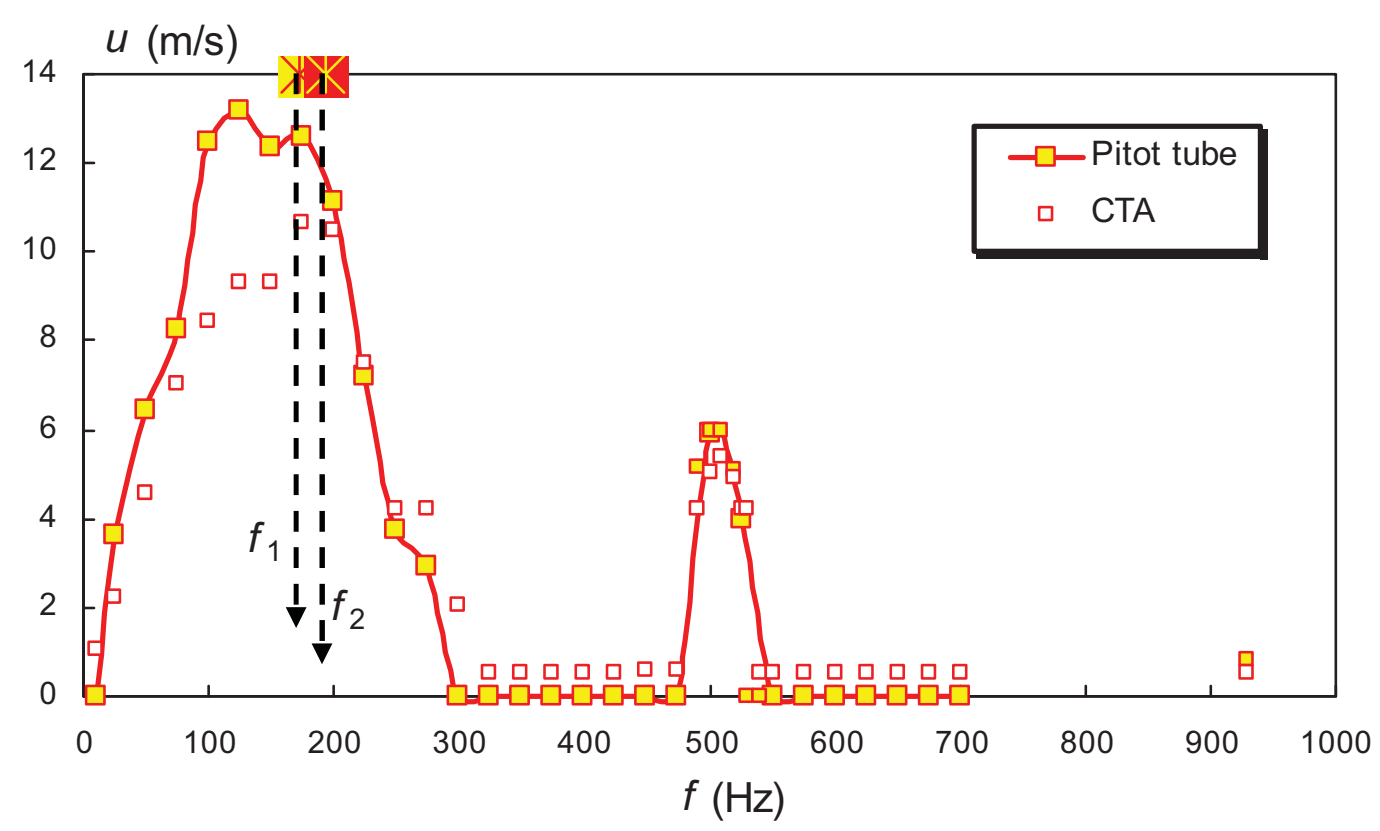

Figure 2: Frequency characteristic. 


\subsection{Flow visualization}

Figure 3 demonstrates visualization of the S] existence threshold $[32,33]$ at $S=127$ (i.e. $f=100 \mathrm{~Hz}$ ). Figures $3\left(\mathrm{a}\right.$ and $\mathrm{b}$ ) shows $\mathrm{S}$ Js at $L_{0} / D=3.29$ and 0.64 . On the other hand, Fig. 3(c) shows the sub-critical stage: the vortices are not propagated downstream for $L_{0} / D=0.47$, thus $\mathrm{S}$ ] cannot be created for so small $L_{0} / D$. This result agrees very well with our expectation because the threshold of the SJ existence can be considered about $L_{0} / D=0.5,[32,33]$.

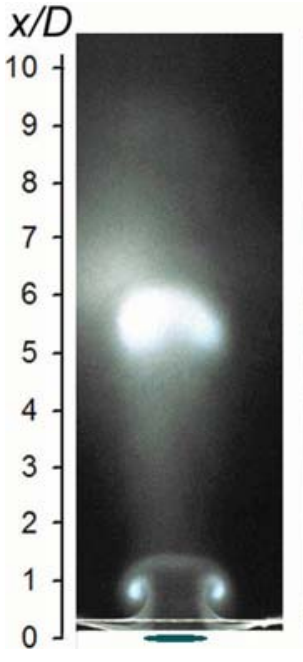

(a)

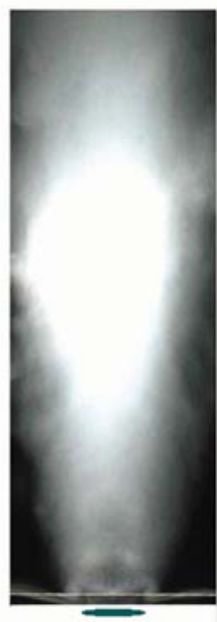

(b)

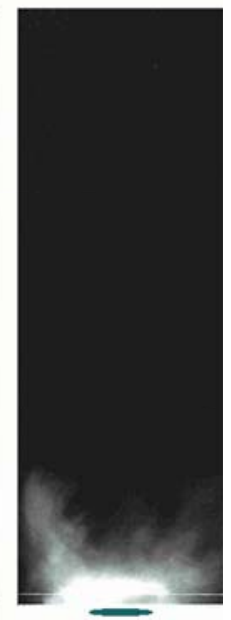

(c)

Figure 3: Phase-locked visualization at $S=127,(f=100 \mathrm{~Hz})$, adapted from [33]:

(a) synthetic jets at $L_{0} / D=3.29$, (i.e. $R e=17000$ ),

(b) synthetic jets at $L_{0} / D=0.64$, (i.e. $R e=3300$ ),

(c) no synthetic jet for $L_{0} / D=0.47$, (i.e. $R e=2400$ ).

Similar behavior can be seen in Fig. 4. These six pictures show visualization of the jet at $S=90$ (i.e. $f=50 \mathrm{~Hz}$ ), at $L_{0} / D=2.97 \div 0.48$. Figs. $4(\mathrm{a}, \mathrm{b}, \mathrm{c}, \mathrm{d}$ and e) show SJ but Fig. $4(f)$ represents the behavior of the jet below the critical stage (i.e. similar case as Fig. 3 (c) mentioned above).

Figures 5 and 6 demonstrate the SJs at $S=127$ (i.e. $f=100 \mathrm{~Hz}$ ), $L_{0} / D=2.33$ and at $S$ $=90$ (i.e. $f=50 \mathrm{~Hz}), L_{0} / D=2.74$, respectively, during one cycle. Pictures have been taken with the equal steps of the phase-shift $45^{\circ}$. In these pictures, the extrusion and suction part of the cycle can be easily recognized: the extrusion part runs from phase angle $0^{\circ}$ to approximately $180^{\circ}$ and then the suction begins. On the basis of these pictures, the phase-shift for visualization of the SJ existence threshold (Figs. 3 and 4) has been chosen, so that all phase locked photos in Fig. 3 and 4 are made at the maximum extrusion velocity of the cycle (i.e. approximately $90^{\circ}$ ). 


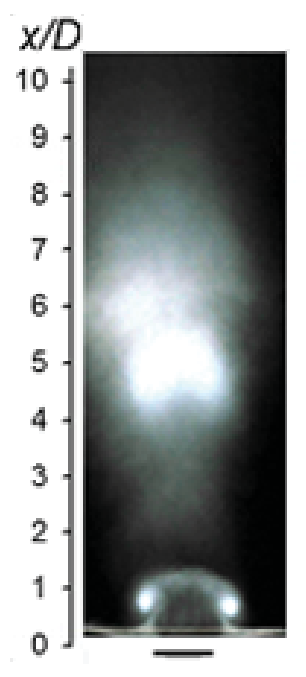

(a)

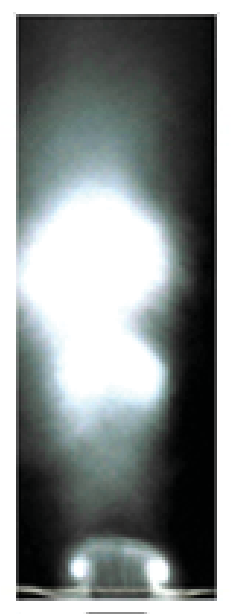

(b)

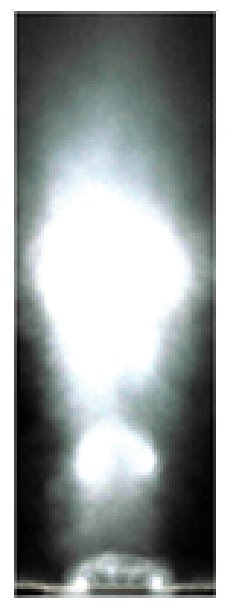

(c)

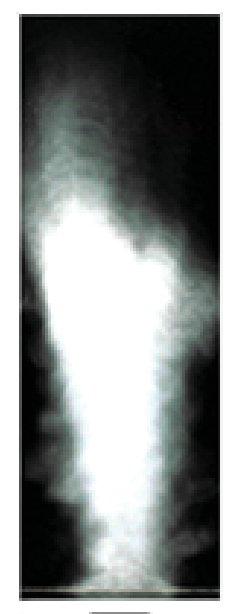

(d)

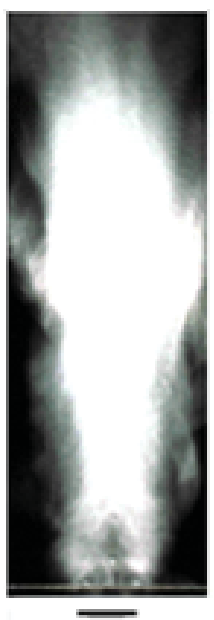

(e)

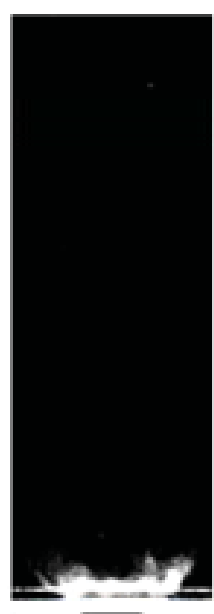

(f)

Figure 4: Phase-locked visualization at $S=90,(f=50 \mathrm{~Hz})$ :

(a) synthetic jets at $L_{0} / D=2.97$, (i.e. $R e=7700$ ),

(b) synthetic jets at $L_{0} / D=2.73$, (i.e. $R e=7050$ ),

(c) synthetic jet for $L_{0} / D=1.68$, (i.e. $R e=4350$ )

(d) synthetic jets at $L_{0} / D=0.76$, (i.e. $R e=1950$ ),

(e) synthetic jets at $L_{0} / D=0.55$, (i.e. $R e=1450$ ),

(f) no synthetic jet for $L_{0} / D=0.48$, (i.e. $R e=1250$ ).
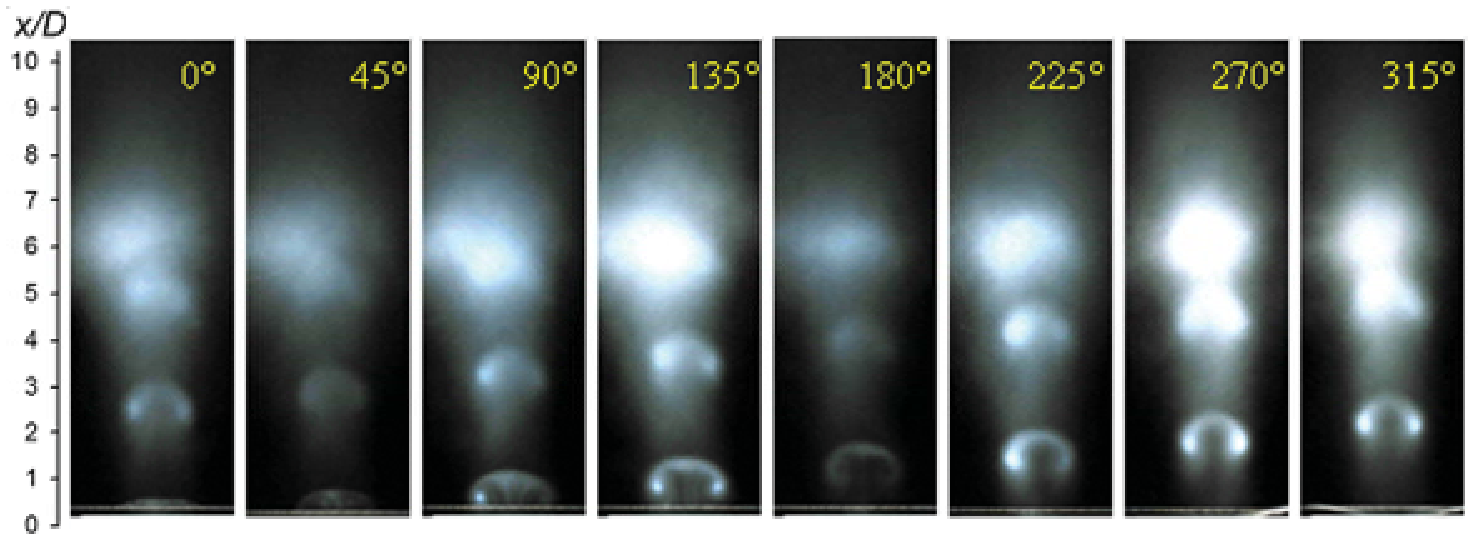

Figure 5: Phase-locked visualization at $S=127(f=100 \mathrm{~Hz}), L_{0} / D=2.33$. 


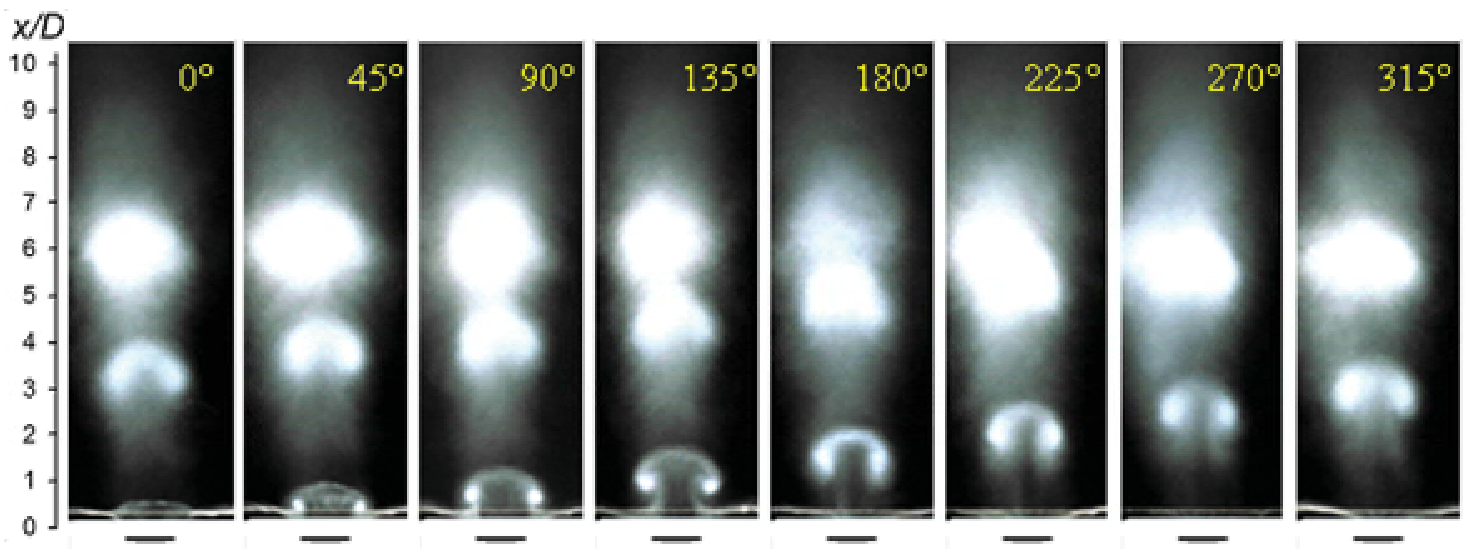

Figure 6: Phase-locked visualization at $S 90(f=50 \mathrm{~Hz}), L_{0} / D=2.74$.

For the comparison purposes, figures 7 and 8 show visualization of instantaneous pattern of flow field. These pictures were taken using photo flash light. Figure $7(a, b)$ shows the SJs at $S=127$ (i.e. $f=100 \mathrm{~Hz}$ ), $L_{0} / D=3.29$ and at $S=127$ (i.e. $f=100 \mathrm{~Hz}$ ), $L_{0} / D=$ 1.75 , respectively. Figure $8(\mathrm{a}, \mathrm{b})$ shows the $\mathrm{S}$ Js at $S=90$ (i.e. $f=50 \mathrm{~Hz}$ ), $L_{0} / D=2.97$ and at $S=90$ (i.e. $f=50 \mathrm{~Hz}$ ), $L_{0} / D=1.68$, respectively. Against to the Figs. $3-6$, these pictures show the fluctuation deviations of the individual cycles as was mention in the paragraph 2.

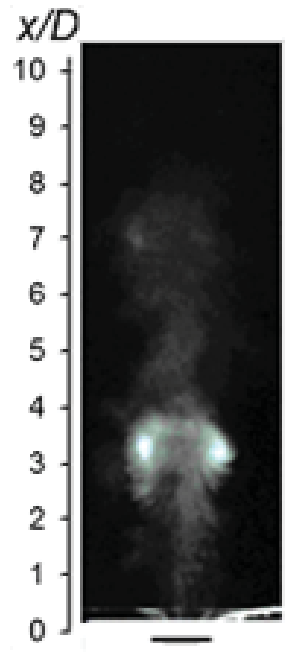

(a)

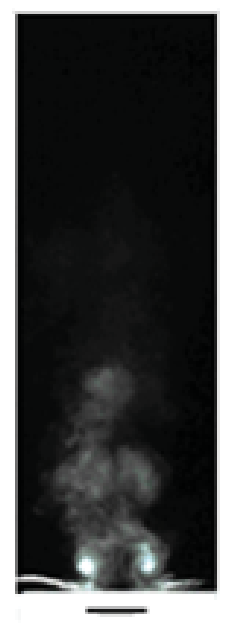

(b)

Figure 7: Visualization of instantaneous pattern of synthetic jets at $S=127$, $(f=100 \mathrm{~Hz})$ :

(a) $L_{0} / D=3.29$, (i.e. $\operatorname{Re}=17000$ ),

(b) $L_{0} / D=1.75$, (i.e. $R e=9000$ ). 


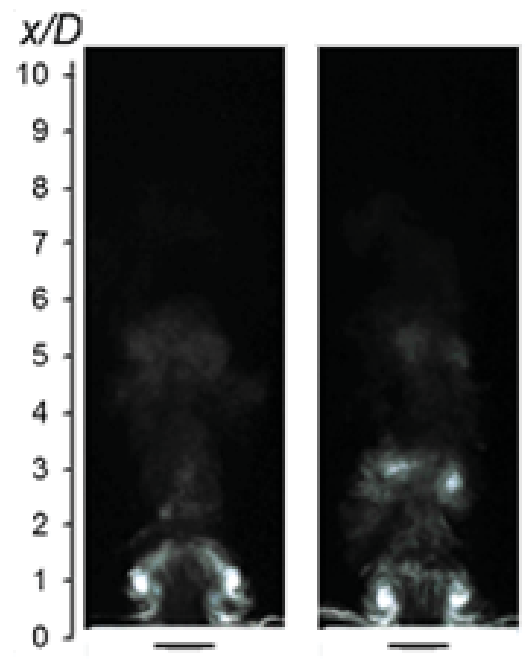

(a)

(b)

Figure 8: Visualization of instantaneous pattern of synthetic jets at $S=90$, $(f=50 \mathrm{~Hz})$ :

(a) $L_{0} / D=2.97$, (i.e. $\operatorname{Re}=7700$ ),

(b) $L_{0} / D=1.68$, (i.e. $R e=4350$ ).

\section{CONCLUSION}

Visualization of synthetic jets at higher Stokes numbers ( $S=90$ and 127 ) has been performed using smoke-wire technique. To quantify parameters of the jet at chosen operating points, the hot-wire anemometry was used.

Behavior of the SJ near its critical stage has been demonstrated. The critical stage (the threshold of SJ existence) was identified by means of visualization. For small value of $L_{0} / D \leq 0.48, \mathrm{~S}$ J was never formed. For higher value of $L_{0} / D \geq 0.55$, SJ was always reliably generated. Behavior of the present synthetic jet agrees very well with expected results from available literature.

\section{ACKNOWLEDGEMENT}

We gratefully acknowledge the support of the GAASCR (IAA 200760801) and GACR (P101/11/J019). 


\section{REFERENCES}

[1] Cheng K.C.: A history of flow visualization: chronology, Journal of Flow Visualization and Image Processing, Vol. 4, No. 1, 1950, 9-27.

[2] Řezníček R.: Visualizace proudění. Academia, Praha, 1972 (in Czech).

[3] Mueller T.J.: Smoke visualization. In: Handbook of Flow Visualization, Chapter 7, Ed. W-J. Yang, Hemisphere Publ., New York, Washington, London, 1989.

[4] Corke T., Koda D., Drubka R., Nagib H., A new technique for introducing controlled sheets of smoke streaklines in wind tunnels. IEEE 77CH 1251-8 AES, 1977.

[5] Trávníček Z., Příklady použití kouřové visualizace proudění v experimentální mechanice tekutin (Examples of smoke visualization in the experimental fluid mechanics), VVI (Vytápění větrání instalace) 11, 5, 2002, 230-233 (in Czech).

[6] Trávníček Z., Peszyński K., Hošek J., Wawrzyniak S., Aerodynamic and mass transfer characteristics of an annular bistable impinging jet with a fluidic flipflop control, Int. J. Heat Mass Transfer vol. 46, No. 7, 2003, 1265-1278.

[7] Dauphinee T.M., Acoustic air pump, Rev. Sci. Instrum, Vol. 28, No. 6, 1957, 456.

[8] James R.D., Jacobs J.W., Glezer A., A round turbulent jet produced by an oscillating diaphragm, Phys. Fluids, Vol. 8, No. 9, 1996, 2484-2495.

[9] Smith B.L., Glezer A., The formation and evolution of synthetic jets, Phys. Fluids Vol. 10, 1998, 2281-2297.

[10] Mallinson S.G., Reizes J.A., Hong G., An experimental and numerical study of synthetic jet flow, The Aeronautical Journal, Vol. 105, No. 1043, 2001, 41-49.

[11] Lee C.Y., Goldstein D.B., Two-dimensional synthetic jet simulation, AIAA J., Vol. 40, No. 3, 2002, 510-516.

[12] Glezer A., Amitay M., Synthetic jets, Annu. Rev. Fluid Mech. Vol. 34, 2002, 503529.

[13] Tesař V., Zhong S., Efficiency of synthetic jet generation, Transactions of the Aeronautical and Astronautical Society of the Republic of China, Vol. 35, No. 1, 2003, 45-53.

[14] Arwatz G., Fono I., Seifert A., Suction and oscillatory blowing actuator modelling and validation, AIAA J., Vol. 46, No. 5, 2008, 1107-1117.

[15] Yassour Y., Stricker J., Wolfshtein M., Heat transfer from a small pulsating jet, Proceedings of the 8th International Heat Transfer Conference, Vol. 3, Hemisphere Publ., San Francisco, USA, 1986, 1183-1186.

[16] Kercher D.S., Lee J-B., Brand O., Allen M.G., Glezer A., Microjet cooling devices for thermal management of electronics, IEEE Trans. Compon. Packaging Technol. Vol. 26, No. 2, 2003, 359-366.

[17] Trávníček Z., Tesař V., Annular synthetic jet used for impinging flow masstransfer, Int. J. Heat Mass Transfer, Vol. 46, No. 17, 2003, 3291-3297.

[18] Mahalingam R., Rumigny N., Glezer A., Thermal management using synthetic jet ejectors, IEEE Trans. Compon. Packaging Technol. Vol. 27, No. 3, 2004, 439444.

[19] Gillespie M.B., Black W.Z., Rinehart C., Glezer A., Local convective heat transfer from a constant heat flux flat plate cooled by synthetic air jets, Trans. ASME J. Heat Transfer, Vol. 128, 2006, $990-1000$. 
[20] Arik M., An investigation into feasibility of impingement heat transfer and acoustic abatement of meso scale synthetic jets, Applied Thermal Engineering Vol. 27, 2007, 1483-1494.

[21] Valiorgue P., Persoons T., McGuinn A., Murray D.B., Heat transfer mechanisms in an impinging synthetic jet for a small jet-to-surface spacing, Exp. Therm. Fluid Sci. Vol. 33, No. 4, 2009, 597-603.

[22] Chaudhari M., Puranik B., Agrawal A., Heat transfer characteristics of synthetic jet impingement cooling, Int. J. Heat Mass Transfer, Vol. 53, No. 5-6, 2010 1057-1069.

[23] Persoons T., McGuinn A., Murray D.B., A general correlation for the stagnation point Nusselt number of an axisymmetric impinging synthetic jet. Int. J. Heat Mass Transfer, Vol. 54, No. 17-18, 2011, 3900-3908.

[24] Timchenko V., Reizes J.A., Leonardi, E., An evaluation of synthetic jets for heat transfer enhancement in air cooled micro-channels. Int. J. Numer. Methods Heat Fluid Flow, Vol. 17, No. 3, 2007, 263-283.

[25] Trávníček Z., Dančová P., Kordík J., Vít T., Pavelka M., Heat and mass transfer caused by a laminar channel flow equipped with a synthetic jet array. Trans. ASME, Journal of Thermal Science and Engineering Applications Vol. 2, No. 4, 2010, 041006-1 - 041006-8.

[26] Trávníček Z., Vít T., Tesař V., Hybrid synthetic jet as the non-zero-net-massflux jet, Phys. Fluids Vol. 18, No. 8, 2006. 081701-1-081701-4.

[27] Trávníček Z., Fedorchenko A.I., Wang A-B., Enhancement of synthetic jets by means of an integrated valve-less pump, Part I: Design of the actuator, Sens. Actuators A, Vol. 120, No. 1, 232-240.

[28] Trávníček Z., Tesař V., Wang A-B., Enhancement of synthetic jets by means of an integrated valve-less pump, Part II. Numerical and experimental studies. Sensors and Actuators A, Vol. 125, No. 1, 2005, pp. 50-58.

[29] Trávníček Z., Tesař V., Kordík J., Performance of synthetic jet actuators based on hybrid and double-acting principles. Journal of Visualization, Vol. 11, No. 3, 2008, 221-229.

[30] Tesař V., Configurations of fluidic actuators for generating hybrid-synthetic jets. Sensors and Actuators A, Vol. 138, 2007, 394-403.

[31] Jabbal M., Liddle S.C., Crowther W.J., Active flow control systems architectures for civil transport aircraft. J. Aircraft, Vol. 47, No. 6, 2010, 1966-1981.

[32] Holman R., Utturkar Y., Mittal R., Smith B.L., Cattafesta L., A formation criterion for synthetic jets, AIAA Journal, Vol. 43, No. 10, 2005, 2110-2116.

[33] Trávníček Z., Broučková Z., Kordík J., Formation criterion for synthetic jets at high Stokes numbers. AIAA J. (submitted).

[34] Kordík J., Trávníček Z., Šafařík P., Experiments on resonance frequencies of synthetic jet actuators. Journal of Flow Visualization and Image Processing, Vol. 17 , no. 3, 2010, 203-214. 